\title{
The Impact of Need for Cognition on Self-Esteem of .P.G.Students.
}

\author{
PreranaHuli*, Dr. Vijaylaxmi .A. Aminbhavi** \\ *P.G. Student, Department of Psychology, Karnatak University, Dharwad, Karnataka State, India. \\ **Head of Department, Department of Psychology, Karnatak University, Dharwad, Karnataka State, India.
}

\begin{abstract}
This Study was conducted to find out the significant difference between high and low Need for Cognition on Self-Esteem of P.G. Students. The sample for the study consisted of 80, 40 male and 40 female students studying in department of social sciences and sciences. The tools that were used are Need for Cognition scale developed by Cacioppo and Petty (1982). It measures the individuals' tendencies to pursue and enjoy the process of thinking. Self-Esteem scale developed by Rosenberg (1965) was used to assess the SelfEsteem of the Students.

Results revealed that the students with high Need for Cognition have significantly high Self-Esteem $(t=2.20 p<0.05)$. Further analysis revealed contribution on demographic variables like Parental Education and Number of Siblings have contributed significantly to have high Need For Cognition.Parental Education have Positive impact on students Need for Cognition and Stay in the hostel have a negative impact on students Need for Cognition. Two Siblings have positive impact on the students need for cognition.
\end{abstract}

Keywords: Need for Cognition and Self-Esteem

\section{Introduction \\ "What is most thought provoking in these thought provoking times is that we are still not thinking".}

Martin Heidegger.

COGNITION:In science, Cognition is a group of mental processes that includes attention, memory, producing and understanding language, solving problems and making decision. Cognition is studied in various disciplines such aspsychology, philosophy linguistic science and computer science. Usage of term varies in different disciplines for example in psychology and cognitive science: it usually refers to an information processing view of individual's psychological functions. It is also used in a branch of social psychology called social cognition to explain attitudes, attribution and group dynamics.

The term cognition comes from the Latin verb "Congnosco" (con with +gnosco = know), itself a loanword from the ancient Greek verb gnosko meaning 'learning' (noun gnosis= knowledge ,so broadly , 'to conceptualize' or 'to recognize'. Cognition is a faculty for the processing of information applying knowledge and changing preferences.

Cognition or cognitive processes can be natural or artificial, conscious or unconscious. These processes are analyzed from different perspective within different context notably in the fields of linguistic, anesthesia, neurology and psychiatry, psychology, philosophy, anthropology systematic computer science and creed. Within psychology or philosophy the concept of cognition is closely related to abstract concepts such as mind and intelligence. It encompasses the mental functions, mental processes (thoughts) and states of intelligent entities.( human elaborative groups, human organizations, highly autonomous machines and artificial intelligence.)

\section{THINKING:}

Thought generally refers to any mental or intellectual activity involving an individual's subjective consciousness. It can refer either to the act of thinking or the resulting ideas or arrangements.

Thinking allows beings to make sense of or model the world in different ways and to represent or interpret it in ways that are significant to them, or which accord with their needs, attachments, objectives, plans, commitments, ends and desires.

In common language the word to think covers numerous and diverse psychological activities. It often refers merely to the act of being conscious of something, especially if that thing is outside the immediate environment.("It made me think of my grandmother"). It's sometimes synonym for 'tending to believe' especially with less than full confidence ("I think that it will rain, but I am not sure"). At other times it denotes the degree of attentiveness ("I did it without thinking"). Many other mental activities many of which shade into each other can be covered by the word, such as interpreting, evaluating, imaging, planning and remembering. Psychologists have concentrated on thinking as an intellectual exertion aimed at finding an answer to a question or the solution of a practical problem. Cognitive psychology is branch of psychology that investigates internal 
mental processes such as problem solving, memory and language. The school of thought arising from this approach is known as cognitivism which is interested in Gestalt psychology of Maxwertheimer, WolfgangKholer and Kurt koffka and in the work of Jean Piaget, which provided a theory of stages that describes children's cognitive development.

Thinking involves critical thinking and reasoning. Critical thinking is that it questions, assumptions. It is part of the formal education processes and is increasingly significant as student's progress through university to graduate education.

Reasoning is a capacity that human beings have to make sense of things, to establish and verify facts and to change or justify changes, institutions and beliefs. Reasoning is associated with thinking, cognition and intellect. Reasoning helps in understanding truth and false, cause and effect and what is good or bad.

\section{Different types of thinking.}

Critical thinking; this is convergent thinking. It assess the worth and validity of something existent. It involves precise, persistent, objective analysis.

Creative thinking; this is divergent thinking it generates something new or different. It involves having a different idea that works as well as better than previous idea.

Convergent thinking; this type of thinking is cognitive processing of information around a common point, an attempt to bring thoughts from different directions into a unit or common conclusion.

Divergent thinking; In this type of thinking, it starts from a common point and move outward into variety of perspectives.

Inductive thinking; this is processes of reasoning from parts to the whole, from examples to generalization.

\section{NEED FOR COGNITION:}

The need for cognition in psychology is a personality variable reflecting the extent to which people engage in and enjoy effortful cognitive tasks.

Individuals who have high need for cognition are the ones who engage in discussions, assessing the ideas and comprehending of problems and solutions. These individuals by their very nature are more likely to involve themselves in the intellectually demanding tasks. Individuals with low need for cognition by their very nature are not really motivated to engage themselves in the intellectually demanding tasks. These individuals rather prefer to process the information heuristically, that is low elaboration (Dole and Sinatare 1998 p. 117).

Need for Cognition is closely related to openness to ideas, typical intellectual engagement and epistemic curiosity. It has also been positively related to Self-esteem and negatively related to social anxiety. Apparently psychological research on need for cognition has been conducted using self-report tests where research participants answered series of statements such as "I prefer my life to be filled with puzzles that I must solve and were scored on how much they felt the statements represented them. The results from the above suggest that people who are high on need for cognition score slightly higher in verbal intelligence tests but not higher in abstract reasoning tests.

Need for Cognition has been incorporated in Epstein dual system theory of judgment called CognitiveExperimental Self- theory. The theory proposes that people have two information processing system a rational system and a experiential system. The rational system is thought to be logical verbal, and relatively unemotional. The experimental system is thought to be inductive based on image and highly reliant on emotion. A modified version of the need for cognition scale has been used to assess individual differences in the rational system, where as the experiential system has been assessed using a scale called faith in intuition. The results revealed that the two systems are correlated and hence independent of each other.

Need for cognition is in line with the amount of thinking that is involved in making a decision. Irrespective of the level of need for cognition, individuals are vulnerable to the bias in judgment. People low in need for cognition

tend to show more bias while the basis is due to relying on heuristic. People high in need for cognition tend to be more affected by biases that are generated by effortful thought.

The research also indicates that individuals high in need for cognition are more susceptible to the creation of false memories associated with certain learning tasks.

A bias associated with low need for cognition is the halo effect, phenomena in which attractive or likeable people tend to be related as superior on a variety of other characteristics example intelligence.

Research has concluded that individuals high in need for cognition are less likely to attribute higher social desirability to more attractive individuals and are high life satisfaction.

\section{SELF-ESTEEM}

Self-esteem is a term in psychology to reflect a person's overall evaluation or appraisal of his/her own worth. Self-esteem encompasses beliefs for instance, ('I am Competent', 'I am Worthy') and emotions such as 
triumph, despair, pride and shame. The self concept is what we think about the self. Self-esteem could be positive or negative evaluation of the self, and its how we feel about it. Baumeister (1997) described self concept as totally perception which people hold about himself/herself. Early researchers used self concept as a descriptive construct such as "I am an athletic"- Rosenberg (1979).

Self-esteem is one of the crucial factors for a person's success or failure. It seems to be part of one self because a person's self-esteem can be seen in his/her behavior. While an individual takes up a task lot of times it not only reflects the talent but also the confidence and self-esteem.

The Self-esteem is important for everyone irrespective of age because it's one of the driving forces for progress. When we talk about P.G students' Self-esteem perse it is extremely important for them to be successful.

High Self-esteem amounts to well being and their academic success. Research that is done in this area direct towards the factors those contributes to have either high or low levels of self-esteem.

One of the factors that contribute to high self-esteem is minimal stress. It helps the students to work hard. And also the support and encouragement from the family will enhance the self-esteem and performance of the students. On the other hand if the stress levels are high and if the students are not able to cope with the stress they end up having low self-esteem. The family background which involves financial problems, social problems will have immense influence on the students' academic success and well being.

The students while their goals are clear and know how to go about the goal, Self-esteem is naturally high. Students in any case when feel lonely and pessimistic most of times their self-esteem is low.

Students generally undergo stress either because of academics or their personal issues like how they look or they have their own insecurities that they need to combat. In such situations the students are expected to seek someone's help or confide to someone close to so that, their self-esteem and wellness is not disturbed.

Students need to persistently work hard because to stay confident and have high self-esteem they need to put efforts towards that. They have to constantly check on their thoughts, self belief and social support to be balanced and to perform.

Research indicates that high self-esteem improves the efficacy of the students which in turn leads to high life satisfaction. Low self-esteem leads to poor efficiency, lack of confidence and low life satisfaction.

Hence students need to be positive, tolerant, and appreciative of their selves and their life. This will harbor an optimistic personality who will be successful in both academics and personal life.

\section{Review Of Literature}

This study was conducted by Benedict.T. Mcwhirter (2011) to examine the relationships among types of longitudinal and learned resourcefulness, Self-esteem and gender among a sample of 625 college students. The scales were administered and factor analysis of R-UCLA revealed that it measures 2 distinct types of loneliness, intimate loneliness and social loneliness. Results of multiple Regressions revealed that self-esteem and gender significantly predicted the experience of global loneliness, intimate loneliness and social loneliness. Learned resourcefulness predicted social loneliness.

Davis, Stephen F(1992) et al conducted the research to study the relationship between optimistic-pessimism, loneliness and level of self-esteem in college students. The sample of the study is 155 undergraduate students. The results reveal that loneliness was positively related with pessimism. But negatively related with optimism . Loneliness and pessimism were negatively related with self-esteem, while optimism was positively related with self-esteem. Optimism and pessimism were negatively related.

Diener, Ed, Diener Marissa (1995) conducted the research and data from 31 nations were collected on selfesteem, life satisfaction and satisfaction with specific domains like friends, family and finances. The authors assessed whether cross culturally variations in the strength of associations were related to societal dimensions including incomes and individualism. At the national level, individualism correlated -24(ns) with heterogeneity and .71(p<.01) with wealth. At the individual level Self-esteem was correlated .47 for the center sample. This relationship, however, was moderated by the individualism of the society. The associations of financial, friends and family satisfactions with life satisfaction and with self-esteem also varied across nations. Financial satisfaction was a stronger correlate of life satisfaction in poorer countries. It was found that life satisfaction ratings except for financial satisfaction, varied between slightly positive and fairly positive.

Gloria, Alberta M. (2001)et al conducted the study to investigate the influence of self beliefs, social support and comfort in the university environment on the academic non persistence decisions of 83 American Indians graduates. The results reveal that social support was the strongest predictor, followed by comfort in the university environment and then self-beliefs. Students who perceived being mentored were most likely to report decreased non persistence decisions. Similarly students who had more positive perceptions of the university environment were likely to make less non persistence. Finally higher Self-esteem and greater college related Self-efficacy was associated with decreased non persistence decisions.

A study conducted by Hudd, Suzanne (2000) et al on effects on healthy habits, health status and selfesteem at Ivy Leaguecolleges, this study analyzed the results of a random survey of 145 Ivy League 
undergraduate students. In this study they addressed the demographic groups who are vulnerable to stress. Secondly they addressed relationship between stress and health behavior, lastly students with low Self-esteem. The results reveal that female and non athletes were more stressed. And they were less likely to practice healthy habits and more prone to bad habits. The students under great stress were low in self-esteem and poor health status.

A longitudinal comparative study of the self-esteem of students: in Regular and Special education classes were conducted by James Battle, and Tom Blowers (1982). The Sample of the study was 158 boys and girls in regular and special classes. Results reveal that subjects in special education classes experienced greater gains in selfesteem and perception of ability of scores than boys and girls in regular classes.

A study conducted by Jennifer Crocker (2002) examined the costs of pursuit of self-esteem for the self, in terms of competence relatedness and mental health and for others. It's hypothesized that external contingencies of self-worth require validation from others are unreliable as a basis of self-esteem and hence are associated with greater costs. Data from a longitudinal study of an ethnically diverse sample of 642 college freshman support view that contingencies of self worth shape how students spend their time and the prediction that external contingencies of self- worth especially appearance, have high costs for stress, aggression, drug and alcohol use and symbols of disordered eating.

In a research conducted by Jennifer (2003) et al on Self-esteem and contingencies of self worth reveal that contingencies of self worth uniquely contribute to academic and financial difficulties experienced by college freshmen beyond level of self-esteem and other personality variables. Low self-Esteem on the other hand seems to attribute to later social difficulties.

A Study was conducted to determine the role of self-esteem in the relationship between stress and Ingratiation. In this study the sample was 65 psychology graduate students were analyzed to explore how stress relates to Self-esteem, mood and daily habits. The results suggest that sleep patterns exercise habits and predictor of stress. The study was conducted by Kekewu, Chenwel, LI, Diance, and E.Johnson (2011).

The present study aimed at examining the nature of thinking styles, self-esteem and socio-economic status. The sample consisted 694 students age ranging from 17-45 from the university HongKong participated. It was found that when age was controlled, thinking styles and self-esteem overlap. Further more students who used thinking styles that are creativity-generating and more complex tasks. Students who reported higher self-esteem tend to be students from higher socio-economic status families. This study was conducted by Li-fangzhang and Gerard A. Positiglione (2001).

This study reports an investigation into the sources and levels of stress in relation to locus of control and Self-esteem in university students by RedaAbouserie (2006). The sample of the study consisted of 672 students (202 males and 473 females) second year graduate students. The results indicated that examination and results were highest cause of stress and studying for exams also caused serious stress. There are significant differences between female and male students. Female students were found to be more stressed. Results also indicated a significant positive correlation between locus of control and academic stress, suggesting that students with external beliefs are more stressed than those with internal. A significant negative correlation between self-esteem and both academic life stress emerged indicating that students with high self-esteem are less than those with low.

The present study focused on the relationships between self-efficacy beliefs and college student satisfaction. The study was conducted by S.JosephDeluitz and W.Bruce Walsh (2002). Sample consisted of 312 undergraduates. The results revealed that all three measures of Self-efficacy were significantly associated with, college satisfaction. Regression analysis and analysis of variance revealed that college self-efficacy significantly associated with college satisfaction, whereas the other two measures of Self-efficacy did not account for any unique additional variance.

\section{NEED FOR THE STUDY:}

\section{Methodology}

Thinking is an act of intellectual activity involving an individual's subjective consciousness. This study tries to find out how people enjoy thinking or otherwise. The Need for Cognition scale tries to measure the enjoyment in thinking and relate it to self-esteem that measures the present individual's Self-worth.

\section{OBJECTIVES}

1) To find out significant difference between students with low need for cognition and high need for cognition on their self-esteem.

2) To identify the demographic factors which significantly contribute to need for cognition and Self-esteem. 


\section{RESEARCH PROBLEM}

a) Do Students with low need for cognition and high need for cognition differ significantly from each other on their Self-Esteem.

b) Do Demographic factors such as Age, Gender, Birth-Order, Number of Siblings, Students Education, Parents Education, Occupation, Income, Early Background, Religion, Caste, Health Status, Type of Stay P.G Students Contribute Significantly to Need for Cognition and Self-Esteem.

\section{HYPOTHSES:}

Based on the above objectives and raised questions following hypotheses are formulated and tested further:

$\mathrm{Ha}_{1}$ : There is significant difference between students with low Need for Cognition and high Need for Cognition on their Self-Esteem.

$\mathrm{Ha}_{2}$ : Demographic factors such as Age, Gender, Birth-Order, Number of Siblings, Students Education, Parents Education, Occupation, Income, Early Background, Religion, Caste, Health Status, Type of Stay P.G Students Contribute Significantly to Need for Cognition and Self-Esteem.

\section{DATA COLLECTION:}

In the present study the primary data was collected from social science and science departments. The Quota sample of present study consists of N=80 PG Students, out of whom 40 from social science section and 40 from science .Both the groups consists of equal number of male and female students (20 each). The samples were administered with the Need for Cognition and Self-Esteem scales.

\section{TOOLS:}

Need for Cognition Scale developed by Cacioppo and Petty in (1982) was used to measure individual's tendencies to pursue and enjoy the process of thinking that is for their Need for Cognition. Self-esteem scale developed by Rosenberg (1965) used to measure Self-esteem of P.G students.

Statistical Techniques Applied ' $\boldsymbol{t}$ ' test is applied to determine the significant difference between students with low need for cognition and high need for cognition.

Step-Wise Multiple Regression Analysis, This analysis is performed to determine the contribution of demographic factors to the need for cognition and self-esteem. This is done with the help of computer package.

\section{Results And Discussions. \\ TABLE 1 SHOWING MEAN AND STANDARD DEVIATION FOR SELF-ESTEEM SCORES OF STUDENTS WITH HIGH AND LOW NEED FOR COGNITION.}

\begin{tabular}{|l|l|l|l|l|l|}
\hline SL.NO. & VARIABLES & GROUP & $\boldsymbol{N}$ & MEAN & STANDARD DEVIATION \\
\hline 1 & Self-Esteem & Students with high Need for Cognition & 33 & 52.88 & 10.33 \\
\hline & & Students with low Need for Cognition & 47 & 48.00 & 9.33 \\
\hline
\end{tabular}

An observation of the above table reveals that there is much variation that can be observed between the groups. More specifically the students with high need for cognition have above average mean score of 52.88 with the standard deviation of 10.33. The students with low need for cognition have the mean score of 48.00 with the standard deviation of 9.33 .

Students with high need for cognition have above average scores which indicate in an educational context, these personality traits and learned skills particularly the ability to process information efficiently can be linked with greater academic achievement (Sadowski and Gvlgoz, 1996). Furthermore as Sadowski and Cogburn have shown (1997), Individuals who have high scores on need for cognition tend to be more conscientious and more open to experiences than are individuals who have low need for cognition.

To support the above study a research conducted by Jennifer et al reveal that high level of Self-Esteem and contingencies of self worth uniquely attribute to academic and financial condition experienced by college freshmen how self-esteem on the other hand attribute to social difficulties.

Further more study conducted by Rensnick, Harvey et al (1970) reveal that, more the students were clear about their vocation better was their Self-Esteem. With reference to the students with high Need for cognition they have Self-Esteem which means they have number of good qualities; they can do things as well as other people. Their Self worth is high and have positive attitudes.

Students with low need for cognition who have below average scores would not do academically well. They don't enjoy the thinking process and are not motivated to apply their thinking skills and also their information processing is poor.One of the studies examined the nature of thinking styles, Self-Esteem and Socio-economic status. The results revealed that students who used thinking styles that are creativity-generating and more complex tasks reported higher self-esteem and they belonged to higher socio-economic status Lifangzhang and Gerand A Postiglione (2001) The facts that the students with low need for cognition tend to have low self- 
esteem because they think that they are not good. They are not proud of themselves. They feel useless. Due to their inability they experience failures.

TABLE 2 SHOWS MEAN DEVIATION, STANDARD ERROR OF MEAN, AND t-VALUES FOR SELF-ESTEEM OF STUDENTS WITH HIGH AND LOW NEED FOR COGNITION.

\begin{tabular}{|l|l|l|l|l|l|}
\hline SL.NO & VARIABLE & GROUP & $\begin{array}{l}\text { MEAN } \\
\text { DEVIATION }\end{array}$ & $\begin{array}{l}\text { STANDARD ERROR OF } \\
\text { MEAN }\end{array}$ & $\begin{array}{l}\boldsymbol{t} \text { - } \\
\text { value }\end{array}$ \\
\hline 1 & Self-Esteem & $\begin{array}{l}\text { Students with high and low need for } \\
\text { cognition }\end{array}$ & -4.88 & 2.21 & $-2.20^{*}$ \\
\hline
\end{tabular}

A perusal of the above table reveals that students with high need for cognition and low need for cognition differ significantly from each other in their self-esteem. The ' $t$ ' value obtained are $(t=2.20 ; p<0.05)$. As' $t$ ' value indicates that there is significant difference between groups.

From the above facts it can be inferred that the students with high need for cognition have significantly higher self-esteem, because students' self-worth is really high. When the students self worth is high, he is naturally satisfied with himself. He feels that he is imbibed with number of good qualities which makes him feel confident and competent. Hence the students' attitude towards self and life is positive.

In one of the study conducted by S Joseph Deluitz and W.Bruce Walsh (2002) revealed that students' selfefficacy beliefs were associated to their satisfaction with college. Furthermore study conducted Gloria, Alberta.M (2001) et al. reveal that student social support was the strongest prediction followed by comfort in the university environment and then Self-belief crucial role students who felt monitor felt comfortable were likely to make decreased non persistent decisions.

In contrast to the above facts the students with low need for cognition tend to have significantly lower Self-esteem that is perhaps because there is paucity of confidence and self worth in the students. They eventually start feeling worthless, they aren't proud of themselves, they are inclined to feel that they are failures and wish that they could respect themselves more. Hence the students' attitude towards themselves and life is negative.

In one of the study conducted determined the role of Self-Esteem in relationship with stress and ingratiation. The results reveal that there was a correlation between Stress and Self-Esteem and ingratiation, the sleep patterns, exercise habits and negative moods were significant correlates and predictors of stress. Kekewu, Chenwel, Lz, Diance, E Johnson(2011).

The longitudinal comparative Study by James Battle and Tom Blowers (0982) reveal that Self-esteem of students with special education experienced greater gains in self-esteem and perception than the students with regular education.

V

TABLE 3 SHOWS RESULTS OF STEP-WISE MULTIPLE REGRESSION ANALYSIS OF THE FACTORS SIGNIFICANTLY CONTRIBUTING TO NEED FOR COGNITION.

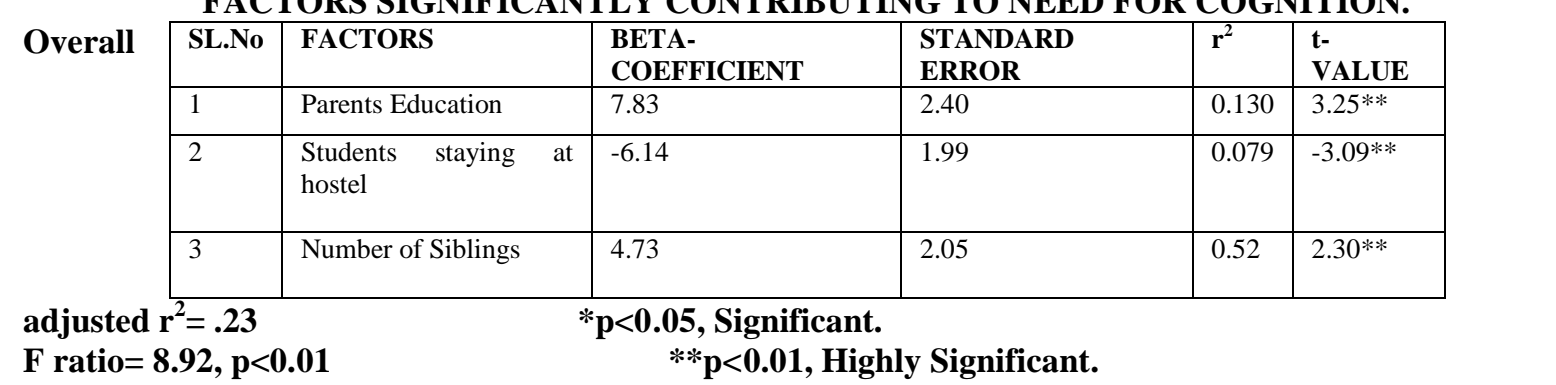

An observation of the above table reveals that out of several factors parents education, Stay at hostel and number of siblings significantly contributed to $0.23 \%$ of variance on Need for Cognition of P.G students, which is found to be very highly significant $(\mathrm{F}=8.92 ; \mathrm{p}<0.01)$.

Further those students who are staying at hostel are found to have significantly low need for cognition ($3.09 ; \mathrm{p}<0.01)$ compared to their counterparts. The students who have two siblings are found to significantly high need for Cognition $(\mathrm{t}=2.30 ; \mathrm{p}=<0.05)$.

Parent's education and number of siblings have highly significantly contributed to the variance on need for cognition. The students with graduated parents are perhaps showing high need for cognition due to the encouragement and facilities provided by the parents to explore and experience the knowledge world.

Research was conducted by Diener, ED; Diner Marissa(1998). Data from 31 nations were collected on selfesteem life satisfaction, Satisfaction with specific domains like friends, family, and finances; the results reveal that association of domain varied across nation. Financial satisfaction was stronger correlate of life satisfaction in poor countries. It was found that life satisfaction ratings except for financial satisfaction varied between slightly positive and fairly positive. 
From the above study we can understand that family support, financial condition, friends and satisfaction with life plays an important role in success of academics or life in general.

Further students staying in hostel showed low need for cognition because of various reasons. Students staying at home would have most of their primary needs met that would lead to high need for cognition.

A study conducted by Davis, Stephen(1992) et al reveals that loneliness was positively related with pessimism. But it was negatively related with optimism.Loneliness and pessimism were negatively related with self-esteem. Optimism is positively related with self-esteem.

The above study supports the results that students who stayed at hostel felt lonely and pessimistic. Their Selfesteem and need for cognition would be naturally low.

Another study conducted by Benedict.T.Mcwhirter(2011) to examine the relationship among types of loneliness and learned resourcefulness, Self-esteem and gender among a sample of 625 college students. The results of multiple regressions reveal that self-esteem and gender significantly predicted the experience of global loneliness, Intimate loneliness and social loneliness. Learned resourcefulness predicted social loneliness.

Students who have two siblings are found to have significantly high need for cognition which means parents are able to take greater care of their children, compared to students with more than two siblings, where parental attention and resources get diluted.

\section{Conclusions}

The Students with higher Need for Cognition have significantly higher Self-Esteem. They have better academic achievement and positive attitudes their life. Their self worth is high and also they are more open to new experiences.

In contrast, the students with low Need for Cognition have significantly lower Self-Esteem. Their self beliefs are distorted. Their information processing is poor. They have negative attitudes and are likely failures.

Students' whose parents have completed graduation level graduation and those students who have two siblings have significantly high Need of Cognition .Perhaps due to the encouragement, amenities from the family and their assiduousness help them to have high need for cognition.

Further students staying at hostel have low need for cognition.Apparently they would feel pessimistic and lonely without family. They would over indulge with friends resulting in lack of concentration on studies, Compared to students staying at home with parents.

\section{SOCIAL IMPLICATIONS}

- The results imply that there is need to improve the need for cognition in order to enhance the selfesteem of students.

- Further interventions through counseling can be provided to students to enhance the need for cognition.

\section{Acknowledgement}

It is to acknowledge that this is an original piece of research work conducted by me under the guidance of Dr. Vijaylaxmi .A. Aminbhavi, as part of my M.A thesis.

I take this opportunity to thank authors of Need for Cognition scale by Cacioppo and Petty(1982); and SelfEsteem scale by Rosenberg (1965) respectively.

Finally I thank all the Post-Graduate Students who participated in this Study.

\section{References}

[1]. Benedict .T. Mcwchirter (2011): Loneliness, Learned Resourcefulness and Self-Esteem in college students. Journal of counseling and Development.

[2]. Davis, Stephen F et al (1992): The relationship between optimism-permessism; loneliness and level of self-esteem in college students. College Student Journal Vol 26(2) 244-247.

[3]. Diener, Ed; Diener,Marissa(1995): Cross-Cultural correlates of life Satisfaction and Self-esteem; Journal of Personality and Social Psychology. Vol 68 (4) Apr 653-663.

[4]. Gloria, Alberta M et al (2001): Influences of Self-beliefs, Social Support and Comfort in the university environment on the academic non persistence decisions of American Indian Undergraduates. Cultural Diversity and Ethnic Minority Psychology Vol 7 (1), Feb 2001, 88-102.

[5]. Hudd, Suzanne, Jennifer et al. Stress at College (2000) : Effects on health habits, health status and self-esteem. College Student Journal Vol 34 (2), 217-227.

[6]. James Battle, Tom Blowers (1982): A Longitudinal Comparative Study of the Self-Esteem of Students in Regular and Special Education Classes. J Learn Disable February Vol . 15

[7]. Jenifer Crocker (2002): The Costs of seeking self-esteem. Journal of Social issues Vol (58) Issue 3,pages 597-615, January 2002.

[8]. Jennifer Crocker and Riia K. Luhtanen (2003): Level of Self-Esteem and Contingencies of Self-Worth; Unique Effects on Academic, Social and Financial problems in college students. Perssoc psycho Bull 29:701.

[9]. Kekewu, Chenwel LI, Diane.E. Johnson(2011): Role of Self-Esteem in the relationship between Stress and Ingratiation . online publication 1 feb 2011. 
[10]. Li-fang Zhang, Gerard.A.Postiglione(2001): Thinking Styles, Self-Esteem and Socio-Economic Status . Personality and Individual Differences Vol 31, Issue 8 December.

[11]. Reda. Abouserie (1994) : Sources and levels of stress in relation to locus of control and self-esteem in university students. Educational Psychology: An International Journal of Experimental Educational Psychology Vol issue 3. Online 29 sep 2006.

[12]. Rensick, Harvey et al (1970): Vocational Crystallization and Self-Esteem in College Students. Journal of Counseling Psychology, Vol 17 (5), 465-467.

[13]. S. Joseph Dewitz and W. Bruce Walsh(2002): Self-Efficacy and College Student Satisfaction. Journal Career Assessment August Vol 10 no 315-326. 